\title{
ANÁLISE ECONÔMICA DO DIREITO POR RICHARD POSNER E OS DIREITOS SOCIAIS: UMA ABORDAGEM CRUZADA
}

\author{
Gabriela Rangel da Silva ${ }^{1}$ \\ André Luiz Staack ${ }^{2}$
}

\section{RESUMO:}

A pesquisa tem como objetivo analisar a aplicabilidade da teoria da "Análise Econômica do Direito" desenvolvida Richard Posner nos Direitos Sociais. Para tanto, fez-se necessário abordar a origem e conceituação da teoria do jurista norte americano, como também conceituar o nascimento e a estruturação dos Direitos Sociais em âmbito internacional e nacional. Ao cruzar os temas depreende-se que os Direitos Sociais possuem uma carga protetiva e assecuratória muito grande em relação à salvaguarda do indivíduo como ser humano, de forma que não cabe uma análise em moldes econômicos de um direito puramente social.

Palavras-chave: Análise Econômica do Direito; Richard Posner; Direitos Sociais

\section{ECONOMIC ANALYSIS OF LAW BY RICHARD POSNER AND SOCIAL RIGHTS: THE CROSS APPROACH}

\begin{abstract}
:
The research has the purpose to analyze the applicability of the theory about "Economic Analysis of Law" Richard Posner on Social Rights. Therefore, it was necessary to approach the origin and concept of North American jurist theory, but also conceptualize the birth and the structuring of social rights at the international and national level. Crossing the issues it is clear from the social rights have a protective and security load too large relative to the protection of the individual as a human being, so it's not possible an analysis on economic, because it's a purely social right.
\end{abstract}

Keywords: Economic Analysis of Law; Richard Posner; Social Rights

\section{INTRODUÇÃO}

O Presente trabalho tem por fulcro a realização de breves considerações sobre a teoria da "Análise Econômica do Direito" desenvolvida por Richard Posner e os Direitos sociais. A análise fixa-se em até que ponto as proposições da teoria podem ser aplicadas em

\footnotetext{
${ }^{1}$ Mestre em Ciência Jurídica pela Universidade Vale do Itajaí. Mestre em Estudos Políticos na Universidad de Caldas - UCaldas - Colômbia. Especialista em Direito do Trabalho e Processo do Trabalho pela Pontifícia Universidade Católica de Porto Alegre - PUCRS. Bacharel em Direito pelo Centro Universitário Franciscano. Advogada OAB/RS.

${ }^{2}$ Mestrando em Ciência Jurídica pela Universidade do Vale do Itajaí - UNIVALI. Mestrando em Estudos Políticos pela Universidade de Caldas - UCaldas/Colômbia. Especialista em Direito Penal e Processual Penal pela UNIVALI . Bacharel em Direito pelo Centro Universitário de Brusque. Oficial de Justiça e Avaliador lotado no Fórum da Comarca de Brusque/SC.
} 
termos de Direitos Sociais, uma vez que Posner não reconhece a categoria Direitos Fundamentais.

Nesse sentido, faz-se necessário entender o surgimento dessa teoria econômica de análise do Direito e as suas conjunturas para que se possa traçar uma conceituação e estruturação das suas bases teóricas.

Após, faz-se uma introdução do pensamento posneriano em a relação com os Direitos Fundamentais, para então fazer um breve relato da origem dos Direitos sociais e a casuística do seu nascimento no mundo jurídico e a consequente concepção valor social do trabalho humano.

Por fim, cruzam-se os temas com o escopo de traçar um paralelo entre as diferentes matrizes jurídicas (norte-americana e brasileira) para então averiguar a possibilidade de aplicação da teoria da Análise Econômica do Direito desenvolvida por Posner nos Direitos Sociais, em especial ao Direito do Trabalho.

Seu objetivo geral é o de constatar a possibilidade de utilização da teoria engendrada por Richard Posner na aplicação dos Direitos Sociais dos trabalhadores por meio de uma ótica econômica.

Os objetivos específicos desta pesquisa baseiam-se na averiguação do contexto histórico e conceitual da teoria da Análise Econômica do Direito por Posner e dos Direitos Sociais como forma de preservação destes últimos e sua melhor aplicação em questões econômicas.

Na elaboração deste estudo buscamos responder ao seguinte questionamento: Pode a teoria da "Análise Econômica do Direito" desenvolvida por Richard Posner ser aplicada em termos de Direitos Sociais?

Com relação à metodologia, foi utilizado o método indutivo, racionalizado pelas técnicas da pesquisa bibliográfica, do referente, das categorias básicas e dos conceitos operacionais.

\section{ANÁlISE ECONÔMICA DO DIREITO: PERCEPÇÕES DE RICHARD POSNER}

A Análise Econômica do Direito, em sentido descritivo, nada mais é do que aplicação conceitual de métodos econômicos para entender o Direito e as suas instituições de 
forma simples e não jurídica. Ela pode se dar de várias formas a depender da vertente a ser seguida: análise a partir da teoria dos jogos, da teoria das escolas públicas, etc. (SILVEIRA, 2009, p.15)

Além disso, existe uma tendência que vai além de somente descrever o Direito por meio dos aspectos econômicos, buscando elementos que participem da formação da teoria jurídica. (SILVEIRA, 2009, p.15)

A escola da Análise Econômica do Direito nasceu nos Estados Unidos da América, mais precisamente, em Chicago, tendo suas origens teóricas em de Ronald Coase, Gary Becker, Guido Calabresi, e Richard Posner, sendo ele o único jurista (LAUDA, 2009). Surgiu como um movimento do Direito estadunidense à crise do Estado do Bem-Estar social, como alternativa a doutrina realista e convencionalista até então dominante. (LAUDA, 2009)

No Brasil, há maior adesão à teoria construída por Richard Posner, devido a um projeto de difusão dessa doutrina em diversas áreas por meio da obra Law and Economics (HEINEN, 2012, p.02).

Segundo Salamana, são objetos de pesquisa de Richard Posner

[...] são as principais doutrinas e construções jurídicas dos tribunais norteamericanos desde a proclamação da Constituição de 1787 até o século 20. E é a partir delas que Posner constrói aquela que se tornaria até hoje sua obra mais importante, Economic Analysis of Law. (SALAMANA, 2012, p.04)

A Análise Econômica do Direito por Posner conceitua-se por utilizar-se dos parâmetros econômicos de modo descritivo, com vista a elucidar o Direito (LAUDA, 2009). Propõe uma visão pragmática para guiar a concessão e de mais atos governamentais, nesse sentir, o Direito deve basear-se no pragmatismo cotidiano e se utilizar menos no pragmatismo filosófico (POSNER, 2010, p.100)

Para ele a economia é a ciência que aborda o modo como o indivíduo trata os recursos limitados em relação com as suas necessidades, ou seja, é necessário um raciocino de custo e benefícios para satisfazer o interesse próprio (POSNER, 2007, p.25). Nesse contexto, Posner entende o indivíduo como um ser puramente racional que busca aumentar ao máximo a suas satisfações, dessa forma o Direito deverá ser composto a partir do modo de pensar do ser humano racional (POSNER, 2007, p.26).

Sin embargo, la marca distintiva del "nuevo derecho y economía" —el derecho y la economía que han surgido desde 1960- es la aplicación del análisis económico al sistema legal en su conjunto: a campos del derecho común; como los cuasidelitos, los contratos, la restitución y la propiedad; a la teoría y la práctica del castigo; al proceso civil, penal y administrativo; a la teoría de la legislación y la regulación; a la aplicación de la ley y la administración judicial, e incluso al derecho constitucional, 
el derecho primitivo, el derecho del almirantazgo, el derecho familiar y la jurisprudencia. (POSNER, 2007, p.55)

A Análise Econômica do Direito deseja desvendar o Direito sob a perspectiva da eficiência econômica, por meio dos aspectos positivos e normativos: o primeiro trata de descrever o fato como é e o segundo versa sobre o que se pode ou não fazer para atingir o objetivo esperado (POSNER, 2007, p.57).

\begin{abstract}
Aunque el economista no puede decir a la sociedad si debe tratar de limitar el robo, sí puede mostrar que sería ineficiente permitir un robo ilimitado; así, puede aclarar un conflicto de valores demostrando cuánto de un valor — la eficiencia- debe sacrificarse para alcanzar otro. O bien, tomando como dada una meta de limitación del robo, el economista debe ser capaz de demostrar que los medios por los cuales ha tratado la sociedad de alcanzar dicha meta son ineficientes: que la sociedad podría obtener mayor prevención, a un costo menor, empleando métodos diferentes. Si los métodos más eficientes no perjudicaran a otros valores, aquéllos serían socialmente deseables, aunque la eficiencia ocupara un lugar bajo en el tótem de los valores sociales. (POSNER, 2007, p.57)
\end{abstract}

Nesse sentido, Richard Posner propõe uma nova maneira de construir o Direito a partir de pressupostos econômicos. Ele se utiliza de três categorias para explicar a teoria do direito, sendo elas: a economia, o pragmatismo e o liberalismo (HEINEN, 2012, p.13-14)

“A Economia é justamente a ciência que estuda e analisa todas as relações que se voltam no sentido de ordenar e também administrar a utilização dos recursos, tendo em vista que estes são escassos" (SALAMANA, 2010, p. 98-99).

Posner descreve o sistema jurídico norte-americano como caracterizado pela impetuosidade, competitividade e objetividade comercial, notadamente marcado pelo materialismo filistino (expressão provavelmente empregada pelo autor no sentido figurado, como sociedade majoritariamente inculta e vulgar, com interesses econômicos despidos de vocação intelectual, de modo que as capacidades de raciocínio adaptativo assumem preponderância, como a inteligência calcada na astúcia, na trapaça e na fraude inequívoca, sem reflexão ética. (ZANON, 2013, p.145) No tocante a Análise Econômica do Direito, a conduta lícita ou ilícita será decidida a partir do interesse e do incentivo para que ela se realize ou não, do raciocino lógico do autor do fato.

Posner se autonomeia pragmático, se filiando ao pragmatismo cotidiano, que para "guiar a adjudicação e outros atos governamentais devem ter suas amaras cortadas da filosofia" (POSNER, 2010, p.03).

[...]pode-se afirmar que Posner trata o pragmatismo jurídico sob um viés cotidiano, como uma corrente de estudos que visa a auxiliar os operadores do direito (juízes, advogados e legisladores) na tomada de decisões sobre políticas públicas, no sentido de promover a maximização da riqueza (em sentido não puramente financeiro) para 
a sociedade, por meio de mecanismos efetivamente úteis no auxílio para a ponderação das consequências futuras de seus atos, segundo uma perspectiva de experimentação real (empírica), orientada para o futuro e desprovida de ilusões filosóficas quanto à possibilidade de confirmação sobre a correção dos resultados.(ZANON, 2013, p 03)

O pragmatismo cotidiano ignora o moralismo e a ideologia, usa o senso comum para resolver os problemas, despreza teorias abstratas de pretensão intelectual (POSNER, 2010, p. 38-41). Posner utiliza-se de um praticalismo, a arte de viver sem fundações. Afinal, o direito para ele é algo instrumental orientado para o futuro, devendo optar-se por ser formalista em bases pragmáticas (SALAMANA, 2012, p.26).

O liberalismo coaduna-se com o modo de pensar o direito por meio da economia, visto que:

[...] Posner adota o liberalismo para evitar, segundo ele, implicações autoritárias possíveis da teoria econômica e do utilitarismo: afirma que a eficiência não tem prioridade sobre a liberdade. Além disso, defende ser o liberalismo a filosofia mais adequada para uma sociedade em que não há consenso quanto aos fundamentos da moral. (HEINEN, 2012, p.08)

A sua propensão pelo liberalismo pauta-se pelo tipo de personalidade que acredita ser preferível aos indivíduos, tais como: autoafirmação e autossuficiência. Uma vez que para ele os juristas deveriam deixar de procurar verdades inatingíveis, relacionadas com categorias altamente abstratas (moral, justiça, igualdade e liberdade) e estar mais preocupados com a realidade. (ZANON, 2013, p.148).

Para Posner "[...]os fenômenos sociais (mediados pelas leis, decisões judiciais, etc.) podem ser explicados a partir dos indivíduos e seu comportamento racional. A ideia de escolha individual racional sustenta, portanto, toda sua análise do direito" (HEINEN, 2012, p.07).

\section{CONSIDERAÇÕES SOBRE A "EFICIÊNCIA" DOS DIREITOS FUNDAMENTAIS NA TEORIA DA ANÁLISE ECONÔMICA DO DIREITO POR RICHARD POSNER: OS DIREITOS SOCIAIS}

Posner no final dos anos 1970, "propôs que o critério de eficiência poderia ser a pedra de toque para a formulação e interpretação do direito" (SALAMANA,2012, p. 4). Ele apresenta como ponto fundante da sua doutrina a maximização da riqueza, sendo a eficiência providencial para o bom funcionamento do sistema. Entretanto, a interdisciplinaridade entre os sistemas jurídicos e econômicos encontram barreiras nos seus traços distintivos: 
É que enquanto a crítica econômica se dá pelo custo, a crítica jurídica se dá pela legalidade; enquanto o direito é exclusivamente verbal, a economia é também matemática; enquanto o direito é marcadamente hermenêutico, a economia é marcadamente empírica; enquanto o direito aspira ser justo, a economia aspira ser científica. (SALAMANA, 2012, p. 4)

O objetivo de Richard Posner é abordar o Direito a partir da análise econômica do custo-benefício para guiar as decisões judiciais. O Direito deve evoluir a fim de possuir maior eficiência. $\mathrm{O}$ autor torna as questões jurídicas em problemas pecuniários, dessa forma a escolha judicial têm um melhor resultado e eficiência, evitando desperdício social. (POSNER, 2010-a). Em suma, Posner busca

[...]desenvolver uma teoria moral que transcenda o utilitarismo clássico e que firme, como critério de julgamento da equidade de uma ação ou instituição, sua capacidade de maximizar a riqueza da sociedade. Essa abordagem permite a conciliação de três princípios éticos concorrentes: a utilidade, a liberdade e até a igualdade. (POSNER, 2010-a, p.138)

Nesse diapasão, compreende-se que o ambiente de produção do Direito, em razão da Análise Econômica, é diverso. A teoria desconsidera os Princípios Fundamentais, tais como: Dignidade da Pessoa Humana, Legalidade, Valor Social do Trabalho, entre outros. A importância dos Direitos Fundamentais é menosprezada, uma vez que os Direitos se tornam discutíveis e negociáveis.

Não obstante, a história da humanidade comprova que a evolução da vida na terra, no passar dos séculos, foi construída pela edificação da proteção do ser humano. Relativizar a proteção do ser humano como pessoa é desconhecer a própria história.

O Estado liberal, período no qual as regras econômicas prevaleciam, trouxe inegáveis benefícios, por exemplo: progresso econômico acentuado, valorização do indivíduo, entre outros. Entretanto, também criou condições próprias para a sua superação, uma vez que a valorização do indivíduo chegou a ultra individualidade, acabando por ignorar a natureza associativa do homem, de modo a dar vez ao egoísmo e a miserabilidade dos trabalhadores.

Nesse modelo, o Estado estava impedido e não apresentava a concepção necessária para a proteção dos menos afortunados, causando uma crescente injustiça social. Sob o pretexto de valorização do indivíduo e da proteção da liberdade, os mais privilegiados estavam cada vez mais protegidos e os hipossuficientes cada vez mais marginalizados (DALLARI, 2012, p.271)

A teoria seguida por Richard Posner propõe a utilização das leis da Economia como meio de racionalização das decisões judiciais. Entretanto, o Direito não regula somente 
questões que envolvem assuntos patrimoniais ou empresariais. Ele transita nos mais variados âmbitos, sejam eles privados ou públicos, de caráter pecuniário ou não.

Assim sendo, fundamentar as decisões judiciais com suporte nas regras de regulamentação da economia enseja ampliar os conflitos ideológicos, sejam eles referentes a Igualdade formal e material, a Legalidade ou até mesmo na tão almejada Fraternidade. A racionalização do Direito pelas "leis" da oferta e procura são bastante limitadas quando se trata de garantias fundamentais e desconsidera totalmente os hipossuficientes e as minorias.

Em que se pese o liberalismo é uma das bases fundantes da Análise Econômica do Direito, para Adam Smith o trabalho era valorizado "como meio de aquisição de riqueza pelos homens, ou seja, era identificado como um motor do capitalismo inserido no marco do Estado Liberal de Direito" (DELGADO, 2006, p.121). Desse modo, os Direitos Humanos, ou seja fundamentais, compõem um importante valor, uma racionalidade de resistência, já que abrem e consolidam espaços de luta pela dignidade humana. (PIOVEZAN, 2006, p. 8)

A dicotomia entre as classes capitalista e proletária levou a construção de uma série de direitos ao longo da história, Direitos Sociais, que necessitam de uma forte carga legal protetiva para que não incorram abusos ao trabalhador como ser humano, sendo assim, na maioria das vezes não são favoráveis à economia, à auto regulação, ao pragmatismo cotidiano, à eficiência e ao liberalismo.

A crescente consciência de proteção do trabalho como um Direito, surge pouco a pouco ao ceder espaço a necessidade dos Direitos Sociais e vêm na linha de desenvolvimento dos Direitos Humanos Fundamentais (SEVERO, 2009, p. 23).

\subsection{DIREITOS SOCIAS NA CONSTITUIÇÃO FEDERAL DE 1988}

Os Direitos sociais são garantias nascidas em meio à construção de uma consciência humanizada do trabalhador, ou seja, um pensamento a parte do econômico, onde a troca de valor versos custo é a regra. Surge assim, um contrato apartado do direito civil, como trata Delgado:

\footnotetext{
As inovações trazidas pelo Direito do Trabalho tem conotação efetivamente revolucionária, se tomados os padrões de estruturação do fenômeno jurídico nos séculos precedentes e, além disso, se considerados os padrões de estruturação desse fenômeno a partir da matriz liberalista construída nos séculos XVIII e XIX no Ocidente.

Em primeiro lugar, trata-se da primeira experiência surgida na História do Direito de um segmento jurídico que fosse expressão de um relevante setor social e econômico subordinado na composição da sociedade, estruturalmente não proprietário, sem efetivo poder institucional. (DELGADO, 2013, p.75-76)
} 
Para se pensar em um direito autônomo, pode-se presumir um razoável montante de normas jurídicas e, nesse sentido, o Estado deixa da abstenção para intervir nas normas trabalhistas, impondo limitações no contrato com a finalidade de proteger o trabalhador e diminuir os abusos do empregador como meio de preservação da dignidade do ser humano.(GARCIA, 2011, p.39)

Em 1917, a Constituição Mexicana, contemplou vários direitos aos trabalhadores no seu Art. 123, como: limitação da jornada de trabalho, salário mínimo, garantia de emprego, proteção para mulheres e crianças entre outros (MAIOR, 2002, p. 5).

Ao final da $1^{\text {a }}$ Guerra, no tratado de Versalhes (28 de junho de 1919), foi criada a OIT (Organização Internacional do Trabalho), « com a função precípua de estudar e promover a melhoria da condição dos trabalhadores no mundo ». Neste mesmo instrumento dedicou- se uma parte especialmente ao trabalho, fixando- se o princípio de que o « trabalho não é mercadoria » e estabelecendo- se a importância de se garantir alguns direitos aos trabalhadores, tais como: jornada de oito horas ; igualdade de salário ; repouso semanal ; inspeção do trabalho; proteção ao trabalho das mulheres e das crianças ; salário mínimo e direito de sindicalização.(MAIOR, 2002, p. 5)

Ainda em 1919, surge a Constituição Alemã de Weimar com o intuito de destacar os interesses trabalhistas e previdenciários.(GARCIA, 2011, p.39) Já, em 30 de maio de 1946, pós-segunda guerra mundial, a OIT é elevada a órgão permanente da ONU, reforçando a preocupação mundial com a distribuição de renda e as condições de trabalho no mundo (MAIOR, 2002, p.6).

O Direito do trabalho desponta como um novo segmento jurídico de restrição ao poder empresarial no plano da contratação e gestão trabalhista, elevando, por meio de normas jurídicas, as condições de inserção da força de trabalho no capitalismo. (DELGADO, 2013, p.77)

No Brasil, a evolução Constitucional do Direito do trabalho começa com a carta de 1824 que aboliu as corporações de ofício. Em 1888, a Lei Áurea acaba com o trabalho escravo no país (Garcia, 2011, p. 41).

O primeiro período significativo na evolução do direito do Trabalho no Brasil foi de 1888 a 1930. (DELGADO, 2011, p. 106) A Constituição de 1891 reconheceu a liberdade de associação, apesar de ser de caráter genérico, passando a considerar licita a organização em sindicatos.(CASSAR, 2013, p. 16) Com Getúlio Vargas, na década de trinta, houve uma maximização de decretos sobre profissões, trabalho das mulheres, salário mínimo, justiça do trabalho, entre outros.(MARTINS, 2011, p. 10) 
O segundo período a se destacar na evolução histórica trabalhista brasileira é a fase da institucionalização do Direito do Trabalho, quando a carta constitucional de 1934 marca um Estado intervencionista de grande atuação na chamada questão social. (DELGADO, 2011, p. 109) A carta foi elaborada sob forte influencia da Constituição de Weimar, foi a primeira que elevou os direitos trabalhistas ao status constitucional, dispondo sobre salário mínimo, jornada de oito horas, repouso semanal, férias anuais remuneradas, proteção do trabalho das mulheres e dos menores de idade. (CASSAR, 2013, p. 18)

A Constituição de 1937 marcou um regime ditatorial, em virtude do golpe de Getúlio Vargas, mantendo o elenco de direitos da constituição anterior e garantiu os direitos coletivos, entretanto, greve e lockout ${ }^{3}$ foram considerados recursos antissociais (CASSAR, 2013, p. 18). Nessa época, também, houve várias leis esparsas sobre o direito do trabalho e, em 1943, foi editado o Decreto-Lei 5.452, aprovando a Consolidação das Leis do Trabalho (CLT). (MARTINS, 2011, p. 11)

A Constituição de 1946 foi considerada democrática e dispôs sobre a participação dos empregados nos lucros da empresa, repouso semanal remunerado, feriados, entre outros direitos. (CASSAR, 2013, p. 18) A Constituição de 1967 manteve os direitos angariados nas Constituições anteriores e objetivou a continuidade da revolução de 1964. (CASSAR, 2013, p. 19)

Com a constituição de 1988 tem-se a plena efetivação dos Direitos trabalhistas na economia e sociedade, alargando várias garantias legais, fortalecendo a atuação dos sindicatos, avançando quanto à paridade entre trabalhadores rurais e urbanos e produzindo uma completa reestruturação do MPT (Ministério Público do Trabalho) com a finalidade de implementar efetividade nas questões justrabalhista. (DELGADO, 2013, p.82) A Constituição Cidadã de 1988 trata dos direitos sociais trabalhistas no Capítulo II, "Dos Direitos Sociais", do Título II, "Dos Direitos e Garantias Fundamentais", abordando esses como cláusulas pétreas do Art. 60, $\S 4^{\circ}$ desta Constituição. (Garcia, 2011, p. 43)

Nesse sentir, os Direitos Sociais passam a preservar a essência do homem trabalhador como um ser humano, já que enquanto Direito Fundamental, respaldam-se no referencial axiológico da Dignidade da Pessoa Humana.

\footnotetext{
3 Art. 722 - Os empregadores que, individual ou coletivamente, suspenderem os trabalhos dos seus estabelecimentos, sem prévia autorização do Tribunal competente, ou que violarem, ou se recusarem a cumprir decisão proferida em dissídio coletivo, incorrerão nas seguintes penalidades: $\S 3^{\circ}$ - Sem prejuízo das sanções cominadas neste artigo, os empregadores ficarão obrigados a pagar os salários devidos aos seus empregados, durante o tempo de suspensão do trabalho.
} 


\section{ABordagem CRUZAda: É POSSíVel a APliCaÇÃo da ANÁlise ECONÔMICA DO DIREITO POR RICHARD POSNER EM ÂMBITO DOS DIREITOS SOCIAIS?}

Como já citado, Richard Posner é um jurista estadunidense, que não possuía como objetivo central da sua pesquisa dissemina-la para além dos Estados Unidos, já que o sistema a ser seguido pelos norte americano é o da Commom Law e as suas conclusões não são necessariamente generalizáveis em termos de Civil Law. Entretanto, o seu raciocínio e metodologia podem ser universalizados em graus mais ou menos proveitosos para além dos limites norte americanos (SALAMANA, 2012, p. 04).

Tal qual o Direito em geral, o ramo trabalhista realiza-se nas experiências democráticas em dois padrões de estruturação jurídica distintos. No Brasil em muito se diferencia do estadunidense, desde matriz doutrinaria oriunda da Civil Law até o forte apelo legalista que tem no país, modelo legislado. (DELGADO, 2013, p.78)

O outro modelo, aplicado na América do Norte que se diferencia do brasileiro é o privatísta pelo forte apelo sindical e pela escassa legislação.

\footnotetext{
Há modelo de normatização autônoma e privatística, originário da pioneira experiência da Inglaterra e que se mostrou importante em países de tradição angloamericana e alguns outros países europeus continentais, baseado menos em legislação estatal do que em normatização advinda da negociação coletiva trabalhista.

Usualmente denominado modelo negociado, esse padrão jurídico, para obter efetivo sucesso, supõe notável reconhecimento à força organizacional e às prerrogativas dos sindicatos de trabalhadores, a par de significativo respeito às organizações de empregados no interior das empresas e de seus distintos estabelecimentos, normalmente de natureza sindical ou sob a direta influência destas entidades, $\mathrm{Na}$ lógica desse modelo cláusulas de manifesto e irreprimível incentivo à sindicalização - comumente consideradas inválidas no segundo modelo democrático existente (de normatização privatística subordinada, ou modelo legislado) - são acolhidas e generalizadas, fortalecendo sobremaneira a presença e a atuação do sindicato. (DELGADO, 2013, p.78)
}

Para Posner a evolução da Common Law americana no sentido de eficiência é à forma encontrada de expressão jurídica de um sistema social voltado para à maximização de riqueza da sociedade, permitindo que o arcabouço jurídico refletisse o sistema econômico, cada vez mais próximo aos resultados de um mercado com competição perfeita. (SALAMANA, 2012, p.05).

No livro "Análise Econômica do Direito", ele trata no capítulo XI da "regulação da relação de emprego", conta que os termos trabalhistas norte americanos são ditados pelos 
sindicatos. Os sindicatos são grupos formados por trabalhadores que se associam com a finalidade de realizar os seus interesses próprios, os quais não podem sofrer intervenções estatais ou privadas (STÜRMER, 2007, p.55).

O grande poder do sindicato é a realização da greve. Para Posner:

\begin{abstract}
La clave para el entendimiento de la economía de las huelgas es el monopólio bilateral del empleador y el sindicato. Un cártel de productores disminuirá la producción pero no hasta cero, por supuesto. Pero si los clientes se reunieran en un cártel de compradores, o si sólo hubiera un cliente, podría responder al cártel de los vendedores amenazando con dejar de comprarle al cártel, con la esperanza de que la amenaza de tal boicoteo induzca al cártel a dar marcha atrás. Un empleador es, en efecto, el único comprador de los servicios de trabajo controlados por el sindicato. $\mathrm{Si}$ el sindicato anuncia que desea un precio mayor por tales servicios, el empleador puede negarse, amenazando en efecto con no comprar nada, y entonces el sindicato, si quiere mantener la credibilidad, deberá decir que el empleador estáintimidando con amenazas que no puede o no le conviene cumplir (bluffing), llamando en consecuencia a los trabajadores a la huelga. Sin embargo, una parte de la obligación legal de negociar de buena fe consiste en abstenerse de anunciar desde el inicio de las negociaciones que la oferta de negociación es "firme", algo que la otra parte debe tomar o dejar. Tal anuncio es una medida de compromiso previo. Si ambas partes recurren a esta medida, no podrán ponerse de acuerdo (la situación se asemeja al juego del"gallina" ¿quién se acobarda primero?) y estallará una huelga.(POSNER, 2007, p. 525)
\end{abstract}

Ao se pensar em greve Posner elenca o grande poder econômico que esta possui, visto que a greve gera prejuízos para o empregador, seja na produção ou no serviço, sendo esse o seu poder de barganha (POSNER, 2007, p.520-525). Entretanto, o cerne da greve é que ela se representa "como ato político e como meio de luta da classe trabalhadora" (MAIOR, 2012, p.2).

Quando a greve acontece em setores públicos obtém uma dimensão muito maior do que quando ocorre no setor privado, ultrapassando, em muitos casos, o interesse de uma categoria especifica de trabalhadores e criando uma grande relevância social. Afinal, por meio da greve muitos direitos sociais foram conquistados, permitindo construir, efetivamente, a democracia. A exemplo disso pode-se citar a conquista do sufrágio universal em diversos países, tais como: Alemanha, Áustria, Estados Unidos, Inglaterra, entre outros (MAIOR, 2012, p.2).

O modelo jurídico justrabalhista que se estruturou no Brasil, teve como base as matrizes europeias continentais e a presença da democracia nos respectivos países. Ele é o da normatização privatística subordinada, também chamado de modelo legislado, baseia-se na forte presença da legislação estatal (Constituição, códigos, leis esparsas, etc), em harmonia à organização sindical e a presença de negociação coletiva, observados o patamar civilizatório 
mínimo imperativo no conjunto econômico e social do país. (DELGADO, 2013, p.78) O sindicato não possui no Brasil a força que possui nos EUA, tendo em vista a vasta carga protetiva já legislada.

O problema da aplicação da Análise Econômica do Direito em questões sociais é o custo/prejuízo do empregador. Entretanto, resta claro que a proteção do trabalhador não se dá por benesse. Ela acontece para que o sistema não se esvaia, ou seja, o capital necessita do trabalhador para que haja produção,

[...] vinculação umbilical da relação de emprego com a genialidade produtiva do capitalismo, que depende estruturalmente de sua presença (mesmo com modulações diferenciadas em sua conformação) para alcançar sua eficiência e seus objetivos. (DELGADO, 2013, p.107)

Desse modo, "a estruturação do sistema produtivo capitalista em torno da relação de emprego propiciou, em um primeiro momento, a continuidade da situação econômica e social de superexploração da força de trabalho [...]"(DELGADO, 2013, p.107). Porém, com o desenrolar dos anos percebeu-se que o Direito do Trabalho não se resume ao simples contraponto ao poder do empregador, mas como um importante ramo de política pública de inclusão social e econômica de grande parte da população no âmbito capitalista (DELGADO, 2013, p.107-108).

“Os direitos trabalhistas têm uma dimensão dupla e combinada, que está bem reconhecida na estrutura normativa da Constituição. São direitos e garantias individuais de seus titulares, os trabalhadores, e, ao mesmo tempo, são direitos sociais" (DELAGADO, 2013, p.49).

Ademais, a redução das garantias sociais provocaria marginalização, que por sua vez gera mais tarde empobrecimento dos setores marginalizados e, com isso, cresce a insegurança e as tensões sociais. (FERRAJOLI, 2007, p.384) Ainda, segundo Ferrajoli "el gasto social dirigido a satisfazer los cuatro tipos de derechos - la subsistencia, la salud, la educación e la información - es a médio y largo plazo la forma de inversión más productiva para el desarrollo económico, civil y político" (FERRAJOLI, 2007, p.384).

Diante disso, percebe-se que o direito do trabalho “[...], cumpre, na vida contemporânea, a função clássica a qualquer segmento do fenômeno jurídico, qual seja, regular condutas, interesses, relações instituições, estruturando a convivência social e pacificando conflitos" (DELGADO, 2013, p.76). E, desse modo, a proteção normativa do trabalhador 
[...] transformou-se no único veículo realmente eficiente de desmercantilização do trabalho no sistema econômico capitalista, diminuindo a tendência incessante do sistema de subordinar a seu império a pessoa humana e sua força laborativa. (DELGADO, 2013, p.77)

O Direito do Trabalho com o seu forte caráter protetivo do ser humano acaba por relativizar o pacta sunt servanda, de forma que o famoso adágio que dita que contrato faz leis entre as partes, torna-se limitado. Por mais que o capitalismo necessite de lucro para que a máquina econômica continue girando, esse não pode ser em detrimento da vida do trabalhador.

A finalidade do Direito e a sua razão social principal é a tutela da vida. Desse modo, não só na proibição de matar que há satisfação dos mínimos essenciais, mas fazer viver e não deixar morrer, ou seja, tão essencial quanto não consentir o morrer é deixar viver. (FERRAJOLI, 2007, p.380-381).

O Direito ao trabalho não se resume ao simples acerto remuneratório, ou seja, trabalho prestado é trabalho pago. O labor é importante na vida do trabalhador, pois além de ser fonte de subsistência, é fonte de inclusão social, de satisfação, de criação, de motivação, de equilíbrio psíquico, entre outros fatores que não podem ser avaliados por termos econômicos.

$\mathrm{O}$ ato de trabalhar não pode ser completamente mercantilizado e consequentemente negociado, pois não se fala de uma máquina e sim de uma pessoa. Os Direitos Sociais nasceram em meio ao aviltamento humano na pretensão do lucro, desse modo, o retorno às leis da econômicas como parâmetro de negociação seria uma afronta a todos aqueles que lutaram para conseguir a garantia desses direitos e um retrocesso em termos de Direitos Fundamentais.

Em síntese, o trabalho possibilita a existência do capitalismo, consequentemente do liberalismo. Contudo, os direitos sociais não podem ser vistos em termos econômicos, visto que, por mais que eles não gerem lucro imediato eles fazem com que haja uma continuidade de produção, já que o trabalhador vive mais e melhor, portanto, produz mais.

Os Direitos Sociais possuem um valor muito maior do que o econômico, pois foram angariados em virtude de muito sacrifício, em meio a greves, lutas e até mesmo guerras. $\mathrm{O}$ valor social do ser humano, sempre será maior do que o econômico.

\section{CONSIDERAÇÕES FINAIS}


A “Análise Econômica do Direito” de Richard Posner conceitua-se pela aplicação de metodologias econômicas no Direito. É uma teoria estadunidense, originada na Escola de Chicago, que busca uma solução para crise do Estado do Bem-Estar Social por meio do retorno do liberalismo. Ela propõe uma visão pragmática cotidiana para guiar os atos governamentais e jurídicos e, desse modo, criar o Direito por meio de pressupostos econômicos.

Os Direitos Sociais surgiram a partir de uma concepção de desmercantilização do trabalho, ou seja, da necessidade de proteção do ser humano como um sujeito digno pelo fato de ser pessoa e trabalhador. Nesse sentir, o Estado passa a impor limitações à organização do trabalho e produzir garantias, regulando condutas e pacificando conflitos.

A possibilidade de aplicação da teoria da Análise Econômica em termos de Direitos sociais resta frustrada devido às inúmeras diferenças estruturais do sistema da Common Law e a Civil Law. Ademais, a constituição do Direito do Trabalho estadunidense é composta basicamente pelo enfrentamento dos sindicatos, já o brasileiro possui um forte apelo legalista e os sindicatos não são tão desenvolvidos.

Além disso, em preceitos econômicos, sabe-se que a econômica trabalha para que haja lucro, entretanto, os Direitos Sociais não são como direitos de propriedade, comercial, entre outros, que podem produzir efeitos adequados economicamente. A aplicação universal da teoria falha em querer ser aplicável a todos os direitos, pois, diferentemente dos citados, os Direitos Sociais, implicam gastos do empregador e do Estado, visto que visam proteger o hipossuficiente.

Os Direitos Sociais necessitam de uma maior proteção estatal, de um Estado mais ativo e presente que regule normas e fiscalize para que não aconteçam abusos. Eles representam um mínimo para que o ser humano possa viver com qualidade e saudável. A aplicação da teoria de Richard Posner implicaria, provavelmente, na precarização de direitos.

Desse modo, conclui-se que a Analise Econômica do Direito não pode basilar os Direitos Sociais dos cidadãos, em especial aos Direitos Trabalhistas, pois eles possuem um caráter protecionista que as regras da economia não são aptas a regular.

\section{REFERÊNCIAS BIBLIOGRAFICAS}


CASSAR, Vólia Bonfim. Direito do Trabalho. $8^{\mathrm{a}}$ ed. Ver. E atual - RJ: Forense: São Paulo. Editora Método, 2013.

DALLARI, Dalmo de Abreu. Elementos de teoria geral do Estado. 31 ed. São Paulo: Saraiva. 2012

DELGADO, Mauricio Godinho. Curso de direito do trabalho. 10. ed. São Paulo, SP: LTr, 2011.

DELGADO, Gabriela Neves. Direito Fundamental ao Trabalho Digno. São Paulo: LTr, 2006.

DELGADO, Mauricio Godinho. Constituição da República e direito fundamentais: dignidade da pessoa humana, justiça social e direito do trabalho./ Mauricio Goudinho Delgado. Gabriela Neves Delgado. - 2. Ed. - São Paulo: LTr, 2013

FERRAJOLI, Luigi. Principia iuris: Teoría del derecho y de la democracia. Traduccion Gius. Laterza \& Figli SpA, Roma, 2007.

GARCIA, Gustavo Filipe Barbosa. Curso de direito do trabalho. 5 ed. Rio de Janeiro: Forense, 2011.

HEINEN, Luana Renostro. A Análise Econômica do Direito de Richard Posner e os pressupostos irrealistas da economia neoclássica. Anais do CONPEDI, Direito e Economia, 2012. Disponível em: < http://www.publicadireito.com.br/artigos/?cod=991c0955da231335 >. Acesso em Jun/2016.

LAUDA, Bruno Bolson. A Análise Econômica do Direito: uma dimensão da crematística no Direito. Revista eletrônica do curso de Direito UFSM, v. 4. N. 1. 2009. Disponível em: <http://periodicos.ufsm.br/revistadireito/article/view/7026 >. Acesso em: Jun/2016. 
MAIOR, Jorge Luiz Souto. A Fúria. Revista LTr, São Paulo, v. 66, p. 1287-1309, nov. 2002. Disponível em: <http://www.jorgesoutomaior.com/uploads/5/3/9/1/53916439/a_furia.pdf>. Acesso em: Jun/2016.

MAIOR. Jorge Luiz Souto. Greve. LTr. Suplemento Trabalhista, v. 48, p. 639-643, 2012. Disponível em: < http://www.anamatra.org.br/index.php/artigos/greve>. Acesso em Jun/2016

MARTINS, Sergio Pinto. Direito do Trabalho. 27ª ed. Editora Atlas, 2011.

PIMENTA, Eduardo Goular; LANA, Henrique Avelino R. P. Análise Econômica do Direito e sua relação com o direito civil brasileiro. Revista da Faculdade de Direito da UFMG. n. 57, 2010. Disponível em:

<http://www.direito.ufmg.br/revista/index.php/revista/article/viewFile/126/118 >. Acesso em Jun/2016.

PIOVESAN, Flávia. Direitos humanos e justiça internacional: um estudo comparativo dos sistemas regionais europeu, interamericano e africano. São Paulo, SP: Saraiva, 2006.

POSNER. Richard. A Economia da Justiça. Tradução Evandro Ferreira e Silva. São Paulo. Editora WMF Martins Fontes, 2010 - a.

POSNER. Richard. Direito, Pragmatismo e Democracia. Tradução Teresa Dias Carneiro; revisão técnica Francisco B. M. Pinto Filho. RJ: Forense, 2010 - b.

POSNER, Richard. El Análisis Económico del Derecho. 2 ed. México: Fondo de Cultura Económica, 2007.

SALAMANA. Bruno Meyerhof. A História do Declínio e Queda do Eficientismo na Obra de Richard Posner. Trinta Anos de Brasil: Diálogos entre Direito e Economia. Ano 2012. Disponível em: $<$ https://works.bepress.com/bruno_meyerhof_salama/35/ >. Acesso em: Jun/2016. 
SEVERO, Valdete Souto. Crise de paradigma no direito do trabalho moderno: a jornada. Porto Alegre: Sergio Antonio Fabris Ed., 2009.

SILVEIRA, Paulo Antônio C. V. da. Direito Tributário e Análise Econômica do Direito: uma visão critica. Paulo Caliendo. RJ: Elsevier, 2009.

STÜRMER, Gilberto. A liberdade sindical na Constituição da República Federativa do Brasil de 1988 e sua relação com a Convenção 87 da Organização Internacional do Trabalho. Porto Alegre: Livraria do Advogado Editora. 2007.

ZANON Júnior, Orlando Luiz. Pós-positivismo: a versão pragmática de Posner. Revista Direito e Liberdade, Natal, v. 15, n. 3, p. 141-170, set./dez. 2013. Quadrimestral. 